\title{
Ethanol Feeding Impairs Innate Immunity and Alters the Expression of Th1- and Th2-Phenotype Cytokines in Murine Klebsiella Pneumonia
}

\author{
David A. Zisman, Robert M. Strieter, Steven L. Kunkel, Wan C. Tsai, Jodi M. Wilkowski, Kathy A. Bucknell, \\ and Theodore J. Standiford
}

\begin{abstract}
The prolonged and excessive consumption of alcohol has been shown to predispose the host to a variety of infectious complications, which may be due, in part, to the inability to produce important activating cytokines. In this study, we assessed the effect of chronic alcohol ingestion on bacterial clearance, survival, and cytokine mRNA and protein expression in mice with Klebsiella pneumonia. Two-week ethanol feeding resulted in substantial impairment in the clearance of K. pneumoniae and decreased survival, compared with CD-1 mice receiving an isocaloric diet without ethanol. No differences were noted between control and ethanol groups in the total numbers or percent of bronchoalveolar lavage fluid neutrophils or macrophages at 24 and $48 \mathrm{hr}$ post-intratracheal $K$. pneumoniae. Importantly, the lungs of alcohol-fed mice with Klebsiella pneumonia displayed a decrease or delay in the expression of interleukin (IL)-12 p35 and p40 mRNA and interferon- $\gamma$ mRNA, respectively, as well as reduced IL-12 and interferon- $\gamma$ protein levels, compared with controls. Conversely, a time-dependent increase in lung $\mathrm{LL}-10 \mathrm{mRNA}$ and protein was noted in ethanol-fed animals, compared with control animals challenged with $K$. pneumoniae. In summary, our studies indicate that ethanol ingestion results in a profound suppression of lung bacterial clearance and decreased survival in Klebsiella pneumonia, which occurs in association with a shift in the balance of lung cytokine mRNA and protein expression favoring Th2- rather than Th1-phenotype cytokines.
\end{abstract}

Key Words: Ethanol, Interleukin-12, Interleukin-10, Tumor necrosis factor, Interferon- $\gamma$.

$\mathbf{T}$ HE PROLONGED and excessive consumption of alcohol predisposes the host to a variety of infectious complications, particularly bacterial infection of the lung. ${ }^{1-9}$ The alcohol-induced impairment in lung antimicrobial host defense is due to several factors, including alteration in both innate and acquired immune responses. Specifically, acute ethanol intoxication has been shown to impair the mobilization, adherence, and metabolic function

From the Departments of Medicine (D.A.Z., R.M.S., J.M.W., KA.B., T.J.S.), Pediatrics (W.C.T.), and Pathology (S.L.K.), Division of Pulmonany and Critical Care Medicine, University of Michigan Medical School, Ann Arbor, Michigan.

Received for publication March 14, 1997; accepted November 14, 1997

This research was supported in part by the National Institutes of Health Grants AA10571, HL50057, HL31693, HL35276, HL58200, HL57243, and CA66180.

Reprint requests: Theodore J. Standiford, M.D., University of Michigan Medical Center, Department of Internal Medicine, Division of Pulmonary and Critical Care Medicine, 3916 Taubman Center, Box 0360, Ann Arbor, MI 48109-0360.

Copyright (C) 1998 by The Research Society on Alcoholism. of neutrophils [polymorphonuclear leukocyte (PMN) cells] both in vitro and in vivo. ${ }^{5-7,10} \mathrm{In}$ addition, ethanol exposure significantly attenuates the ability of alveolar macrophages to phagocytose and kill bacterial pathogens, in part, by reducing the generation of oxygen-derived free radicals. ${ }^{1,3,7,11}$ Finally, ethanol impairs cell-mediated immune responses by reducing the number and effector cell activities of various $T$-lymphocyte populations. ${ }^{1,3,10}$

The specific cellular mechanism(s) by which ethanol exposure alters the recruitment and/or activation of leukocytes at the site of microbial invasion has not been clearly defined, but is believed to be due, in part, to the inability to produce important activating and chemotactic cytokines. Tumor necrosis factor is a cytokine that is required for effective lung innate and acquired immunity. The acute, but not chronic, infusion of alcohol has been shown to attenuate lipopolysaccharide (LPS)-induced increases in serum tumor necrosis factor (TNF), ${ }^{5,6,8}$ as well as the induction of TNF in bronchoalveolar lavage fluid (BALF) after the intratracheal administration of LPS or live bacterial organisms. ${ }^{5} \mathrm{We}$ and others have recently shown that Th1-phenotype cytokines, including interferon- $\gamma(\mathrm{IFN}-\gamma)$ and interleukin (IL)-12, are required signals in host defense against bacterial, mycobacterial, fungal, and parasitic pathogens, whereas the expression of the Th2-phenotype cytokine IL-10 is detrimental to lung innate and cell-mediated immunity. ${ }^{12-22}$ Conflicting data exist regarding the effect of alcohol on the expression of Th1 cytokines. For example, Alak and associates ${ }^{2.3}$ found that prolonged alcohol feeding significantly inhibited the production of IFN- $\gamma$ and soluble IL-2 receptor from retroviral-infected murine splenocytes. In contrast, acute ethanol treatment has recently been shown to augment the expression of IL-12 from activated human monocytes. ${ }^{24}$ The only study examining the effects of ethanol on Th2-phenotype cytokines indicates that the in vitro incubation of human blood monocytes can stimulate the constitutive and LPS-induced expression of IL-10 from human blood monocytes. ${ }^{25}$

In this study, we assessed the effects of prolonged alcohol consumption ( 2 weeks) on the development of lung inflammation, bacterial clearance, and survival in mice inoculated with $K$. pneumoniae intratracheally (i.t.). In addition, we examined the effects of ethanol consumption on the time- 
dependent expression of Th1 (IFN- $\gamma$ and IL-12)- and Th2 (IL-10)-phenotype cytokine mRNA and protein in the lungs of animals with Klebsiella pneumonia.

\section{MATERIALS AND METHODS}

Animals

Specific pathogen-free CD-1 mice (6- to 12-week-old females, Charles River Breeding Labs.) were used in all experiments. All mice were housed in pathogen-free conditions within the animal care facility at the University of Michigan (ULAM) until the day of sacrifice.

\section{Protocol for Alcohol Feeding}

To assess the effects of alcohol on lung innate immunity, two groups of 6- to 8-week-old female CD-1 received calorie-matched complete liquids diets (Bioserve, Frenchtown, NJ), with the alcohol-fed animals receiving incremental increases in ethanol content in their diet as follows: ethanol $2.2 \%(\mathrm{v} / \mathrm{v}) \times 4$ days, then $4.4 \% \times 4$ days, and then $6.6 \% \times 6$ days. The mice were challenged with $K$ pneumoniae on day 14 of ethanol feeding, and were continued at $6.6 \%$ ethanol until the time of organ harvest or death. The blood ethanol level in alcohol-fed animals at the time of $K$. pneumoniae administration ( 2 weeks of ethanol feeding) was $124.7 \pm 29.4$ $\mathrm{mg} / \mathrm{dl}$. During the 2-week calorie-matched diet, the control mice gained $2.10 \pm 0.11 \mathrm{~g}$, whereas ethanol-fed animals lost $1.07 \pm 0.19 \mathrm{~g}$.

\section{Klebsiella pneumoniae Inoculation}

We chose to use $K$ pneumoniae strain 43816, serotype 2 (ATTC, Rockville, MD) in our studies because $K$. pneumoniae is a common cause of pneumonia in chronic alcohol abusers, and this particular strain has been shown to induce an impressive inflammatory response in mice. ${ }^{1,26-28}$ $K$ pneumoniae was grown in tryptic soy broth (Difco, Detroit, MI) $\times 18 \mathrm{hr}$ at $37^{\circ} \mathrm{C}$. The concentration of bacteria in broth was determined by measuring the amount of absorbance at $600 \mathrm{~nm}$. A standard of absorbencies based on known colony-forming units (CFU) was used to calculate inoculum concentration. Bacteria were pelleted by centrifugation at $3200 \times$ $g \times 30 \mathrm{~min}$, washed $\times 2$ in saline, and resuspended at the desired concentration. Animals were anesthetized with $\sim 1.8$ to $2 \mathrm{mg}$ pentobarbital per animal intraperitoneally. The trachea was exposed, and $30 \mu \mathrm{l}$ of inoculum or saline were administered via a sterile 26 -gauge needle. The skin incision was closed with surgical staples.

\section{Determination of Lung K. pneumoniae CFU}

At the time of sacrifice, plasma was collected, the right ventricle perfused with $1 \mathrm{ml}$ of phosphate-buffered saline, then lungs removed aseptically, and placed in $3 \mathrm{ml}$ of sterile saline. The tissues were then homogenized with a tissue homogenizer under a vented hood. Plasma and lung homogenates were placed on ice, and serial 1:10 dilutions were made. Ten microliters of each dilution was plated on soy base blood agar plates (Difco), incubated $\times 18$ hr at $37^{\circ} \mathrm{C}$, and then colonies counted.

\section{Isolation and Amplification of Cytokine $m R N A s$}

Whole lungs were harvested and immediately "snap-frozen" in liquid nitrogen and stored at $-70^{\circ} \mathrm{C}$. Total cellular RNA from the frozen lungs was isolated by homogenizing the organs with a tissue homogenizer in a solution containing $25 \mathrm{mM}$ Tris ( $\mathrm{pH} 8.0), 4.2 \mathrm{M}$ guanidine isothiocyanate, $0.5 \%$ Sarkosyl, and $0.1 \mathrm{M}$ of 2-mercaptoethanol. After homogenization, the suspension was added to a solution containing an equal volume of 100 $\mathrm{mM}$ Tris ( $\mathrm{pH} 8.0$ ), $10 \mathrm{mM}$ EDTA, and $1.0 \%$ sodium dodecyl sulfate. The mixture was then extracted two times each with phenol-chloroform and chloroform-isoamyl alcohol. The RNA was alcohol-precipitated and the pellet dissolved in diethylpyrocarbonate water. Total RNA was determined by spectrophotometric analysis at $260 \mathrm{~nm}$ wavelength. One micro- gram of total RNA was reversed-transcribed into cDNA utilizing a reverse transcription kit (BRL) and oligo (dT) 12-1 primers. The cDNA was then amplified using specific primers for murine TNF, IFN- $\gamma$, IL-10, IL-12 p35, and IL-12 p40, with $\beta$-actin primers serving as the control housekeeping gene. The sense and antisense primers used had the sequence $5^{\prime}$-CCTGTA-GCC-CAC-GTC-GTA-GC-3' and 5'-TTG-ACC-TCA-GCG-CTGAGT-TG-3' for TNF; 5'-CAG-CGA-CTC-CTT-TTC-CGC-TT-3' and 5'CCT-CAG-ACT-CTT-TGA-AGT-CT-3' for IFN- $\gamma, 5^{\prime}$-CTA-TGC-TGCCTG-CTC-TTA-3' and 5'-ATG-GCC-TTG-TAG-ACA-CCT-3' for IL10, 5'-ACC-TGC-TGA-AGA-CCA-CAG-AT-3' and 5'-GAT-TCT-GAAGTG-CTG-CGT-TG-3' for IL-12 p35, 5'-ATG-TTG-TAG-AGG-TGGACT-3' and 5'-GGA-CTG-CTA-CTG-CTC-TTG-AT-3' for IL-12 p40, and 5'-ATG-GAT-GAC-GAT-ATC-GCT-G-3' and 5'-GAT-TCC-ATACCC-AGG-AAG-G-3' for $\beta$-actin, giving amplified products of $\sim 380$ base pairs (bp) for TNF, 243 bp for IFN- $\gamma, 455$ bp for IL-10, 314 bp for IL-12 $\mathrm{p} 35,384 \mathrm{bp}$ for IL-12 p40, and $812 \mathrm{bp}$ for $\beta$-actin. The amplification buffer contained $50 \mathrm{mM} \mathrm{KCl}, 10 \mathrm{mM}$ Tris- $\mathrm{HCl}$ (pH 8.3), and $2.5 \mathrm{mM} \mathrm{MgCl}$. Specific oligonucleotide primer was added $(400 \mathrm{ng} / \mu \mathrm{l})$ to the buffer, along with $4 \mu \mathrm{l}$ of the reverse-transcribed cDNA samples. The cDNA was amplified after determining the optimal number of cycles. The mixture was first incubated for $3 \mathrm{~min}$ at $94^{\circ} \mathrm{C}$ then cycled at $94^{\circ} \mathrm{C}$ for $30 \mathrm{sec}, 52^{\circ} \mathrm{C}$ to $58^{\circ} \mathrm{C}$ for $30 \mathrm{sec}$, elongated at $72^{\circ} \mathrm{C}$ for $30 \mathrm{sec}$, and final extension of $72^{\circ} \mathrm{C}$ for $5 \mathrm{~min}$. The numbers of cycles performed was $26,32,31,35,35$, and 35 for TNF, IFN- $\gamma$, IL-12 p35, IL-12 p40, IL-10, and $\beta$-actin, respectively. After amplification, the samples were separated on a $2 \%$ agarose gel containing $0.3 \mathrm{mg} / \mathrm{ml}(0.003 \%)$ of ethidium bromide and bands visualized and photographed using UV transillumination.

\section{Statistical Analysis}

Data were analyzed by a Macintosh II computer using Statview II statistical package (Abacus Concepts, Inc., Berkeley, CA). Survival data were compared using the $\chi^{2}$ analysis. All other data are expressed as mean \pm SEM and compared using a two-tailed Student's $t$ test. Data were considered statistically significant if $\mathrm{p}$ values were $<0.05$.

\section{RESULTS}

\section{Effect of Ethanol Consumption on Survival in $\mathrm{K}$. pneumonia}

To assess the effect of ethanol feeding on outcome in Gram-negative bacterial pneumonia, CD-1 mice were fed either a complete liquid diet containing graded doses of ethanol or an isocaloric control diet and then administered $10^{2}$ CFU K. pneumoniae i.t. As shown in Fig. 1, no lethality was observed in control animals until $48 \mathrm{hr}$ post-K. pneumoniae administration, with a gradual decline in survival thereafter. No lethality was observed after 10 days, with nearly $50 \%$ of control animals surviving long-term. In contrast, a marked decrease in both early and long-term survival was noted in animals receiving the ethanol diet, with only $5 \%$ of animals surviving past 7 days.

\section{Effect of Ethanol Consumption on Bacterial Clearance in}

K. Pneumonia

To determine if the increased lethality observed in ethanol-fed mice with Klebsiella pneumonia was attributable to impaired lung bacterial clearance, $K$. pneumoniae $\mathrm{CFU}$ were determined in plasma and lung homogenates obtained from control and ethanol-fed mice $48 \mathrm{hr}$ after the intratracheal challenge with $10^{2} \mathrm{CFU} K$ pneumoniae. Com- 


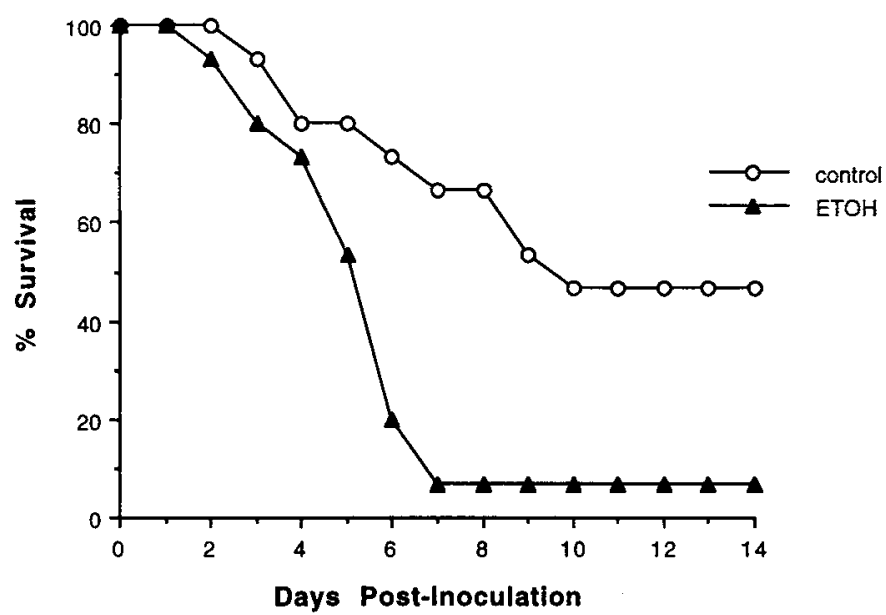

Fig. 1. Effect of ethanol $(E T O H)$ feeding on survival in ethanol and control diet-fed mice after inoculation with $K$. pneumoniae $\left(10^{2} \mathrm{CFU}\right) . p<0.01$ at all time points after day 6 . Experimental, $n=20$ /group.

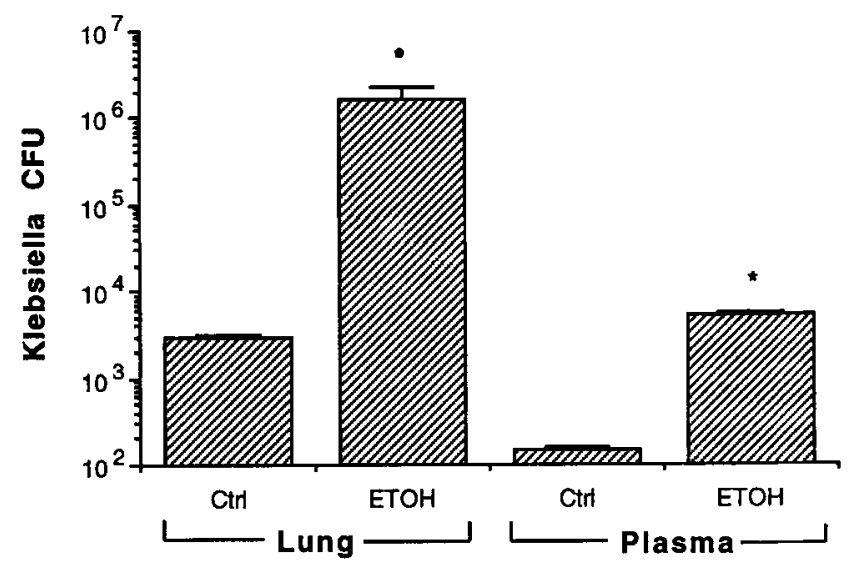

Fig. 2. Effect of ethanol (ETOH) feeding on $K$. pneumoniae $\mathrm{CFU}$ in lung homogenates and plasma $48 \mathrm{hr}$ after inoculation. Log Klebsiella CFU are expressed on the vertical axis. " $p<0.01$, compared with the control (Ctrl) diet-fed animals. Experimental, $n=12 /$ group.

pared with control mice, ethanol-fed animals had a 37-fold increase in numbers of $K$ pneumoniae CFU isolated in plasma $48 \mathrm{hr}$ after $K$. pneumoniae administration (Fig. 2). Even more impressively, a greater than 500 -fold increase in the number of $K$ pneumoniae CFU was found in the lungs of alcohol-fed mice, compared with those animals receiving control diet. These studies indicate that alcohol ingestion results in marked impairment in the host's ability to contain and clear bacterial pathogens after intratracheal challenge.

\section{Effect of Ethanol Consumption on the Generation of Pulmonary Inflammation 24 and $48 \mathrm{Hr}$ after $\mathrm{K}$. pneumoniae Administration}

Having determined that ethanol ingestion markedly impaired bacterial clearance and survival in experimental Klebsiella pneumonia, we next performed studies to assess the effect of alcohol on the influx of inflammatory cells into the airspace post- $K$ pneumoniae administration. As shown in Table 1, the administration of $K$. pneumoniae $10^{2} \mathrm{CFU}$ to
Table 1. BALF Cells and Differentials at 24 and $48 \mathrm{Hr}$ after the Intratracheal Administration of $K$. pneumoniae $10^{2} \mathrm{CFU}$

\begin{tabular}{lcc}
\hline \multicolumn{1}{c}{ Treatment } & $24 \mathrm{Hr}$ & $48 \mathrm{Hr}$ \\
\hline $\begin{array}{c}\text { Total BALF cells }\left(\times 10^{6}\right) \\
\text { Control }\end{array}$ & $2.63 \pm 0.51$ & $3.00 \pm 0.38$ \\
$\quad$ ETOH & $2.47 \pm 0.65$ & $2.76 \pm 0.31$ \\
Total BALF PMN $\left(\times 10^{6}\right)$ & & \\
$\quad$ Control & $0.18 \pm 0.05$ & $0.79 \pm 0.17$ \\
$\quad$ ETOH & $0.26 \pm 0.08$ & $0.78 \pm 0.26$ \\
\% BALF PMN & & \\
Control & $7.20 \pm 0.38$ & $30.4 \pm 5.5$ \\
$\quad$ ETOH & $10.5 \pm 6.8$ & $24.9 \pm 6.9$ \\
Total BALF AM $\left(\times 10^{6}\right)$ & $2.41 \pm 0.43$ & $2.15 \pm 0.37$ \\
$\quad$ Control & $2.20 \pm 0.37$ & $1.97 \pm 0.28$ \\
$\quad$ ETOH & & \\
\% BALF AM & $92.0 \pm 3.9$ & $69.1 \pm 5.5$ \\
Control & $89.2 \pm 6.7$ & $74.8 \pm 6.9$ \\
ETOH & &
\end{tabular}

Control, $\mathrm{CD}-1$ mice receiving control diet; $\mathrm{ETOH}, \mathrm{CD}-1$ mice receiving ethanol diet. Experimental, $n=8-10$ animals/group at the 24-hr time point, 16-18 animals/group at the $48-\mathrm{hr}$ time point.

control mice resulted in an increase in BALF PMN, which was maximal $48 \mathrm{hr}$ post- $K$. pneumoniae administration. Interestingly, we observed no significant differences in either the percent PMN or the total number of BALF PMN at 24 and $48 \mathrm{hr}$ in ethanol-fed animals, compared with their nonethanol-fed counterparts. In addition, ethanol- and nonethanol-fed mice had similar increases in total lung myeloperoxidase activity (as a measure of total PMN content) at 24 and $48 \mathrm{hr}$ post- $K$. pneumoniae challenge (data not shown). Finally, no differences in the percentage or total numbers of BAL macrophages was noted between the two groups at either time point. These studies indicate that alcohol-induced decreases in bacterial clearance and survival was not attributable to diminished influx of leukocytes early in the course of Klebsiella pneumonia.

\section{Effect of Ethanol Consumption on the Time-Dependent} Expression of Th1- and Th2-Phenotype Cytokine mRNAs and Protein Levels during the Evolution of $\mathrm{K}$. pneumonia

Experiments were performed to correlate alcohol-induced alterations in bacterial clearance with the time-dependent expression of important regulatory cytokines in Klebsiella pneumonia. Inoculation of control diet-fed CD-1 mice with $K$ pneumoniae resulted in the expression of TNF mRNA in lung homogenates by 1 day postadministration, with maximal expression occurring at 6 days post-Klebsiella administration (Fig. 3). Interestingly, the expression of TNF mRNA in the lungs of alcohol-fed mice was greater at all time points, with maximal TNF mRNA levels $\sim 3.4$-fold greater than that observed in the lungs of control animals. In contrast, there was a decrease in the expression of both IL-12 p35 and p40 mRNA in alcohol-fed mice at 1, 3, and 6 days postinoculation (maximal $66 \%$ and $42 \%$ decrease, respectively), and a substantial delay in the maximal expression of IFN- $\gamma$ mRNA in the lungs of alcohol-fed mice, compared with controls. Furthermore, a notable induction of IL-10 mRNA was noted at 3 and 6 days post- $K$. pneu- 
Table 2. Cytokine Levels in Whole Lung Homogenates at 48 and $72 \mathrm{Hr}$ Post-K. pneumoniae (102 CFU) Administration

\begin{tabular}{llcc}
\hline Cytokine & \multicolumn{1}{c}{ Group } & \multicolumn{1}{c}{$48 \mathrm{Hr}$} & $72 \mathrm{Hr}$ \\
\hline TNF & Saline & $0.12 \pm 0.02$ & $0.18 \pm 0.04$ \\
& Control + Kleb & $0.58 \pm 0.19$ & $2.39 \pm 0.83$ \\
& ETOH + Kleb & $1.20 \pm 0.30^{*}$ & $3.02 \pm 0.46$ \\
IL-10 & Saline & $0.29 \pm 0.09$ & $0.32 \pm 0.06$ \\
& Control + Kleb & $0.41 \pm 0.08$ & $1.38 \pm 0.13$ \\
& ETOH + Kleb & $0.846 \pm 0.11^{*}$ & $2.09 \pm 0.20^{*}$ \\
IL-12 & Saline & $0.22 \pm 0.02$ & $0.18 \pm 0.03$ \\
& Control + Kleb & $0.65 \pm 0.11$ & $2.64 \pm 0.31$ \\
& ETOH + Kleb & $0.36 \pm 0.07^{*}$ & $1.64 \pm 0.26$ \\
IFN- $\gamma$ & Saline & ND & $0.33 \pm 0.07$ \\
& Control + Kleb & ND & $2.36+0.18$ \\
& ETOH + Kleb & ND & $1.62+0.12^{*}$ \\
\hline
\end{tabular}

Control, animals receiving control diet; $\mathrm{ETOH}$, animals receiving ethanol diet Kleb, animals challenged with $K$. pneumoniae $10^{2} \mathrm{CFU}$; ND, not done. Experimental, $n=3 /$ saline group, $8-16$ per K/ebsiella-challenged mice.

${ }^{*} p<0.05$, compared with control-fed animals.

moniae administration in ethanol-fed mice, whereas no appreciable induction of IL-10 mRNA was noted in control animals challenged with $K$ pneumoniae. To correlate alcohol-induced alterations in lung cytokine mRNA expression with cytokine production, we determined cytokine protein levels in the lungs of alcohol and control-fed animals with Klebsiella pneumonia at 48 and $72 \mathrm{hr}$ post-Klebsiella administration. As shown in Table 2, there was a significant decrease in the levels of lung IL-12 in the alcohol-fed group, compared with controls at $48 \mathrm{hr}$ postbacterial challenge, and a trend toward decreased IL-12 expression at 72 hr $(p=0.07)$. Similarly, IFN- $\gamma$ levels were reduced by $\sim 33 \%$ at $72 \mathrm{hr}$ in alcohol-fed animals, compared with animals receiving control diet $(p<0.05)$. Conversely, a 1.7and 1.5-fold increase, respectively, in lung IL-10 levels, were noted in alcohol-fed mice, compared with controls at 48 and $72 \mathrm{hr}$ post- $K$. pneumoniae inoculation $(p<0.05)$.

\section{DISCUSSION}

Alcohol exposure has been previously shown to predispose the host to a variety of infectious complications, particularly bacterial infection of the lung. ${ }^{1-9}$ In this study, we observed that experimental alcohol ingestion had a profound effect on survival in mice inoculated with $K$ pneumoniae i.t. The increased mortality observed in the ethanolfed group was attributable to impaired bacterial clearance, as we observed a substantial increase in numbers of $K$. pneumoniae CFU in the lungs of alcohol-fed mice, compared with those receiving control diet. Alcohol-induced decreases in bacterial clearance and survival were not attributable to a diminished influx of leukocytes to the site of bacterial invasion during the course of Klebsiella pneumonia, because ethanol- and nonethanol-fed mice had similar increases in total lung myeloperoxidase activity, and no differences in the percentage or total numbers of BALF PMN and macrophages were noted between the two groups. Our findings are consistent with chronic, but not acute, effects of alcohol as reported by Nelson and col-

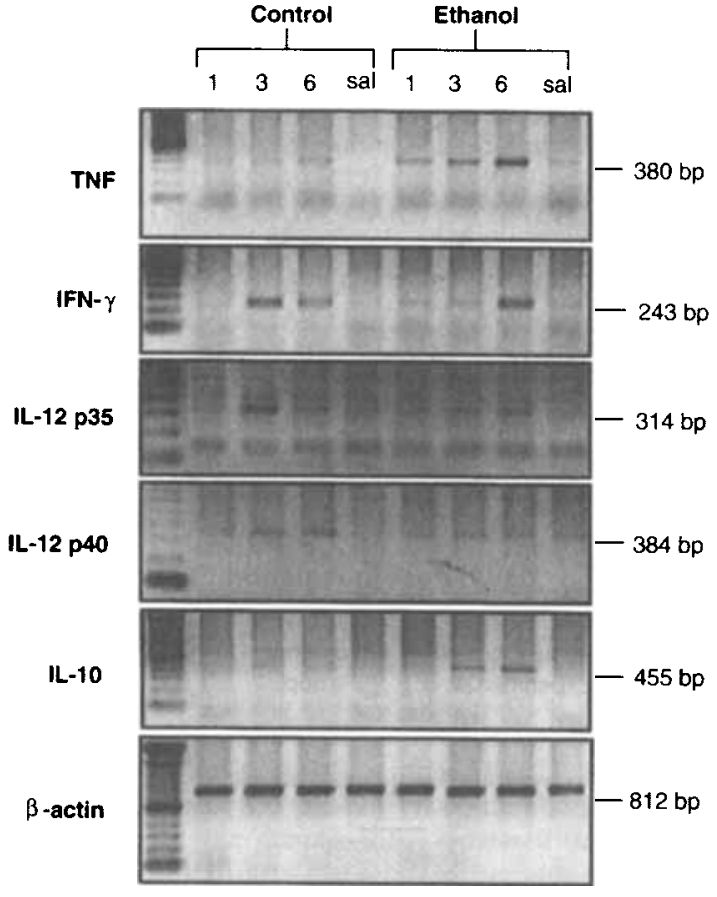

Fig. 3. Effect of ethanol feeding on the time-dependent expression of TNF, INF- $\gamma, \mathrm{IL}-12$ p35 and p40, and IL-10 mRNAs in lung homogenates after the administration of $K$. pneumoniae $10^{2} \mathrm{CFU}$ i.t. Molecular weight markers are found to the left. Each lane represents the lungs of 3 animals combined and is representative of two separate experiments.

leagues. Specifically, these investigators observed reductions in the numbers of BALF PMN in acute ethanol intoxication $2 \mathrm{hr}$ after the intratracheal administration of LPS or $K$ pneumoniae, but no change in BALF PMN in chronic alcoholic rats challenged with LPS i.t. ${ }^{6,7}$ Similarly, Lister and colleagues ${ }^{29}$ observed that treatment of rats with alcohol resulted in a significant impairment in the clearance of Streptococcus pneumoniae from the lungs of rats, even though lung PMN influx was unaltered. Our observations indicate that chronic alcohol consumption diminishes bacterial clearance in the lung by a mechanism other than altered leukocyte recruitment to the site of bacterial infection, and suggest that chronic alcohol use impairs the ability of both resident alveolar macrophages and/or recruited neutrophils to phagocytose and kill bacterial pathogens within the lung, resulting in early dissemination of infection to the bloodstream. ${ }^{30}$ This inability of the host to effectively eliminate invading microbes may be due to alcohol-induced alterations in the expression of important activating cytokines required for effective host defense.

TNF is an essential cytokine required for effective lung innate and acquired immunity against a variety of microbes, including $K$. pneumoniae. ${ }^{31-33}$ The effect of alcohol consumption on TNF expression has been previously investigated. In vivo, acute alcohol intoxication has resulted in significant attenuation of TNF release in response to either endotoxin or intrapulmonary challenge with $K$ pneumoniae ${ }^{5,6,8}$ In contrast, the chronic administration of ethanol ( 6 weeks) had either no effect or actually enhanced the 
peak expression of serum TNF postendotoxin administration. ${ }^{6,8}$ In agreement with the later study, we determined that the expression of TNF mRNA and protein in the lungs of alcohol fed mice was greater or tended to be greater than that observed in the lungs of control animals at all time points post-Klebsiella administration, suggesting an alternative mechanism(s) by which chronic ethanol feeding impairs host defense against bacterial infection of the lung. However, because ethanol has been shown to inhibit the binding of TNF to PMN and other effector cells, ${ }^{34}$ we cannot exclude a component of impaired TNF bioactivity despite enhanced TNF expression.

IL-10 and IL-12 are cytokines that were initially identified as being instrumental to the generation of Th2- and Th1-phenotype immune responses, respectively. ${ }^{12,14}$ More recently, these two proteins have been shown to play an important role in controlling the magnitude of host inflammatory responses. IL-10 exerts potent anti-inflammatory effects both in vivo and in vitro, in part by directly deactivating $P M N$ and macrophages, and by downregulating the expression of several proinflammatory cytokines, including TNF, IFN- $\gamma$, IL- 12 , and several members of the chemokine family. ${ }^{19,35,36}$ Recent studies in our laboratory indicate that passive immunization with anti-IL-10 antibodies in mice with Klebsiella pneumonia resulted in improved survival and bacterial clearance, compared with control animals. ${ }^{20}$ Conversely, the administration of IL-10 to animals with pneumococcal pneumonia results in significant attenuation of bacterial clearance and decreased survival. ${ }^{21}$ In contrast to IL-10, IL-12 promotes Th1 immune responses and represents an important component of acquired immunity against intracellular pathogens. ${ }^{12-14}$ In addition, we have shown that IL-12 is required in the innate immune response against Gram-negative bacterial pathogens, because inhibition of IL-12 decreases bacterial clearance and survival, whereas transient lung IL-12 overexpression utilizing intratracheal adenoviral gene therapy enhances survival in murine Klebsiella pneumonia. ${ }^{15}$ Conflicting data exists regarding the effect of alcohol on the expression of Th1-type cytokines. Specifically, it has been demonstrated that ethanol treatment inhibits IFN- $\gamma$ production in vitro, ${ }^{37}$ and prolonged alcohol feeding significantly inhibits the production of IFN- $\gamma$ from retroviral-infected murine splenocytes. ${ }^{23}$ In contrast, acute ethanol treatment in vitro has recently been shown to augment the expression of IL-12 from activated human monocytes. ${ }^{24}$ In this study, we observed a decrease in the expression of IL-12 p35 and p40 mRNA, and reduced protein levels in the lungs of alcoholfed mice. In addition, we detected a considerable delay in the maximal expression of IFN- $\gamma$ message and a significant reduction in IFN- $\gamma$ protein levels in the lungs of alcohol-fed mice, compared with controls. Furthermore, a substantial induction of IL-10 mRNA and protein expression was noted after $K$. pneumoniae administration in ethanol-fed mice, whereas no apparent induction of this cytokine was noted in control animals. Collectively, these findings indi- cate that chronic alcohol feeding appears to shift the balance in favor of an anti-inflammatory Th2-type immune response by inhibiting the expression of IL-12 and IFN- $\gamma$, while at the same time enhancing the expression of IL-10. Because IL-10 directly inhibits the production of IL-12 and IFN- $\gamma$, we are unable to determine if ethanol mediates direct suppressive effects on Th1-phenotype cytokine expression, or rather indirectly inhibits the expression of these cytokines by directly inducing the in vivo production of IL-10. Furthermore, because IL-12 is a potent inducer of IFN- $\gamma$, it is likely that ethanol-induced reduction in IL-12 is directly linked to the attenuation of IFN- $\gamma$ expression in vivo.

Our data suggests that ethanol-fed animals die due to impaired clearance of bacterial organisms, which we feel is attributable, in part, to enhanced Th2- and diminished Th1-phenotype cytokine responses. However, we cannot exclude the possibility that ethanol-fed mice may be more sensitive to the lethal effects of $K$. pneumoniae-derived LPS, compared with animals receiving a control diet. Enhanced IL-10 expression/administration, or inhibition of Th1-phenotype cytokines, has been shown to be protective in animals challenged with endotoxin. ${ }^{35,36}$ Therefore, these observations would suggest that alcohol-induced changes in cytokine profiles would diminish, rather than augment endotoxin effects.

The mechanism(s) whereby chronic alcohol feeding promotes Th2-type immune responses is not entirely clear. Hormonal changes associated with chronic alcohol consumption may shift the balance in favor of a Th2-phenotype response analogous to that which has been observed in pregnancy. ${ }^{38}$ Alternatively, alcohol-induced alterations on the production and release of arachidonic acid metabolites and, in particular, prostaglandin $\mathrm{E}_{2}\left(\mathrm{PGE}_{2}\right)$, may be responsible for the shift in the cytokine response. Conflicting data exists regarding the effect of alcohol on the expression of $\mathrm{PGE}_{2}$ and other eicosanoids. Ethanol has been shown to increase the release of $\mathrm{PGE}_{2}$ and other prostaglandins from stimulated human blood monocytes and cultured rat Kupffer cells. ${ }^{39,40}$ In contrast, ethanol had an inhibitory effect on the zymosan-stimulated production of $\mathrm{PGE}_{2}$ and other eicosanoids by cultured murine peritoneal macrophages, ${ }^{42}$ whereas chronic alcohol ingestion resulted in no differences in the synthesis of $\mathrm{PGE}_{2}$, leukotriene $\mathrm{B}_{4}$ or 5-(S)-hydroxy-6,8,11,14-eicosatetraenoic acid by stimulated rat peritoneal macrophages and lung tissue homogenates. ${ }^{42}$ There is growing evidence that prostaglandins of the $\mathrm{E}$ series, especially $\mathrm{PGE}_{2}$, alter the expression of important pro- and anti-inflammatory cytokines. ${ }^{43}$ Endogenous or exogenous $\mathrm{PGE}_{2}$ inhibits the release of TNF, IFN- $\gamma$, and IL-12 from various leukocyte populations. ${ }^{44-47}$ Conversely, $\mathrm{PGE}_{2}$ has recently been shown to induce the expression of IL-10 from LPS-stimulated peritoneal macrophages. ${ }^{43}$ Hence, ethanol-induced changes in prostaglandin profiles favoring increases in $\mathrm{PGE}_{2}$ production/bioactivity could account for most, but not all, of the findings observed. A 
notable exception is the apparent induction of TNF in ethanol-fed mice, which may occur as result of desensitization to $\mathrm{PGE}_{2}$ inhibitory effects, or as a result of regulatory influences unrelated to prostaglandins. Preliminary studies in our laboratory indicate that alveolar macrophages from ethanol-fed mice cultured ex vivo produce substantially greater quantities of $\mathrm{PGE}_{2}$ constitutively and when challenged with LPS, compared with similarly treated control alveolar macrophages. Similarly, whole lung $\mathrm{PGE}_{2}$ levels are greater in alcohol-fed animals than that detected in animals receiving an isocaloric control diet (T. Standiford, unpublished observations).

In summary, our studies indicate that ethanol ingestion results in a profound suppression of lung innate immunity in association with a shift in the balance of lung cytokine mRNA and protein expression favoring Th2-, rather than Th1-phenotype cytokines. Further studies are needed to establish causal relationships and to determine if targeted immunotherapy to correct this imbalance will aid in the outcome of ethanol-fed mice with Gram-negative pneumonia.

\section{REFERENCES}

1. Bomalaski JS, Phair JP: Alcohol, immunosuppression, and the lung. Arch Intern Med 142:2073-2074, 1982

2. McLellan AS: A review of the treatment of alcoholism. New Jersey Med 93:39-42, 1996

3. Jerrells TR, Saad AJ, Kruger TE: Ethanol-induced suppression of in vivo host defense mechanisms to bacterial infection, in Freidman $\mathrm{H}$ et al., (eds): Drugs of Abuse, Immunity, and AIDS, vol 335. New York, Plenum Press, 1993, pp 153-157

4. Spitzer JJ, Bagby GJ, Bautista AP, D'Souza NB, Molina PE, Lang $\mathrm{CH}$ : Immunosuppressive effect of alcohol on hepatic parenchymal and nonparenchymal cell functions following endotoxin. Drugs Abuse Immun Immunodefic 255-264, 1991

5. Nelson S, Bagby GJ, Bainton BG, Summer WR: The effects of acute and chronic alcoholism on tumor necrosis factor and the inflammatory response. J Infect Dis 160:422-429, 1989

6. Nelson S, Bagby G, Summer WR: Alcohol suppresses lipopolysaccharide-induced tumor necrosis factor activity in serum and lung. Life Sci 44:673-676, 1989

7. Nelson S, Bagby G, Andresen J, Nakamura C, Shellito J, Summer $\mathrm{W}$ : The effects of ethanol, tumor necrosis factor, and granulocyte colonystimulating factor on lung antibacterial defenses. Drugs Abuse Immun Immunodefic 245-253, 1991

8. D'Souza NB, Bagby GJ, Nelson S, Lang CH, Spitzer JJ: Acute alcohol infusion suppresses endotoxin-induced serum tumor necrosis factor. Alcoh Clin Exp Res 13:295-298, 1989

9. Yamamoto Y, Klein TW, Friedman H: Ethanol affects macrophage production of IL-6 and susceptibility to infection by Legionella pneumophila, in Freidman $\mathrm{H}$ et al., (eds): Drugs of Abuse, Immunity, and AIDS, vol 335. New York, Plenum Press, 1993, pp 169-173

10. MacGregor RR: Alcohol and immune defense. JAMA 256:14741479,1986

11. Bautista AP, D'Souza NB, Lang CH, Bagwell J, Spitzer JJ: Alcoholinduced downregulation of superoxide anion release by hepatic phagocytes in endotoxemic rats. Am Physiol Soc 260:R969-R976, 1991

12. Brunda M: Interleukin-12. J Leukoc Biol 55:280-288, 1994

13. Chehimi J, Trinchieri G: Interleukin-12: A bridge between innate resistance and adaptive immunity with a role in infection and acquired immunodeficiency. Clin Immunol 14:149-159, 1994
14. Howard M, O'Garra A, Ishida H, Malefyt R, De Vries J: Biological properties of interleukin 10. J Clin Immunol 12:239-247, 1992

15. Greenberger M, Kunkel SL, Strieter RM, Lukacs N, Bramson J, Gauldie J, Graham F, Hitt M, Danforth J, Standiford TJ: IL-12 gene therapy protects mice in lethal Klebsiella pneumonia. J Immunol 157: 3006-3012, 1996

16. Laichalk L, Danforth J, Standiford T: Interleukin-10 inhibits neutrophil phagocytic and bactericidal activity. FEMS Immunol Med Microbiol 15:181-187, 1996

17. Cassatella M, Meda L, Bonora S, Ceska M, Constantin G: Interleukin 10 (IL-10) inhibits the release of proinflammatory cytokines from human polymorphonuclear leukocytes. Evidence for an autocrine role of tumor necrosis factor and IL- $1 \beta$ in mediating the production of IL-8 triggered by lipopolysaccharide. J Exp Med 178:2207-2211, 1993

18. Rolph P, Nakoinz I, Sampson-Johannes A, Fong S, Lowe D, Min $\mathrm{H}$, In L: IL-10, T lymphocyte inhibitor of human blood cell production of IL-1 and tumor necrosis factor. J Immunol 148:808-814, 1992

19. Kasama T, Strieter R, Lukacs NW, Burdick MD, Kunkel SL: Regulation of neutrophil-derived chemokine expression by IL-10. J Immunol 152:3559-3569, 1994

20. Greenberger M, Strieter R, Kunkel S, Danforth J, Goodman R, Standiford T: Neutralization of IL-10 increases survival in murine model of Klebsiella pneumonia. J Immunol 155:722-729, 1995

21. Van der Poll T, Marchant A, Keogh C, Goldman M, Lowry S: Interleukin-10 impairs host defense in murine pneumococcal pneumonia. J Infect Dis 174:994-1000, 1996

22. Bermudez LE, Champsi J: Infection with Mycobacterium avium induces production of interleukin-10 (IL-10), and administration of antiIL-10 antibody is associated with enhanced resistance to infection in mice. Infect Immunol 61:3093-3097, 1993

23. Alak JIB, Shahbazian M, Huang D, Wang Y, Darban H, Jenkins EM, Watson RR: Alcohol and murine acquired immunodeficiency syndrome suppression of resistence to Crytosporidium parvum infection during the modulation of cytokine production. Alcohol Clin Exp Res 17:539544,1993

24. Szabo G, Girouard L, Mandrekar P, Catalano D: Acute ethanol treatment augments interleukin-12 production in activated human monocytes. Ann NY Acad Sci 795:422-425, 1996

25. Mandrekar P, Catalona D, Girourd L, Szabo G: Human monocyte IL-10 production is increased by acute ethanol treatment. Cytokine 8:567, 1996

26. Greenberger MJ, Strieter RM, Kunkel SL, Danforth JM, Laichalk LL, McGillicuddy DC, Standiford TJ: Neutralization of MIP-2 attenuates neutrophil recruitment and bacterial clearance in murine Klebsiella pneumonia. J Infect Dis 173:159-164, 1996

27. Bakker-Woudenberg IAJM, Lokerse AJ, ten Kate MT, Mouton JW, Woodle MC, Storm G: Liposomes with prolonged blood circulation and selective localization in Klebsiella pneumoniae-infected lung tissue. J Infect Dis 168:164, 1993

28. McColm AA, Shelley E, Ryan DM, Acred P: Evaluation of ceftazidime in experimental Klebsiella pneumoniae pneumonia: Comparison with other antibiotics and measurement of its penetration into respiratory tissues and secretions. J Antimicrob Chemother 18:599, 1986

29. Lister PD, Gentry MJ, Preheim LC: Ethanol impairs neutrophil chemotaxis in vitro but not adherence or recruitment to lungs of rats with experimental pneumococcal pneumonia. J Infect Dis 167:1131, 1993

30. Jareo PW, Preheim LC, Gentry M: Ethanol ingestion impairs neutrophil bactericidal mechanisms against Streptococcus pneumoniae. Alcohol Clin Exp Res 20:1646, 1996

31. Le J, Vilcek J: Tumor necrosis factor and interleukin-1: Cytokines with multiple overlapping biological activites. Lab Invest 56:234-248, 1987

32. Laichalk L, Kunkel S, Streiter R, Danforth J, Bailie M, Standiford $\mathrm{T}$ : Tumor necrosis factor mediates lung antibacterial host defense in murine Klebsiella pneumonia. Infect Immun 64:5211-5218, 1996

33. Brieland J, Remick D, Freeman P, Hurley M, Fantone J, Engleberg $\mathrm{N}$ : In vivo regulation of replicative Legionella pneumophila lung infection 
by endogenous tumor necrosis factor alpha and nitric oxide. Infect Immun 63:3253-3258, 1995

34. Deaciuc IV, D'Souza NB, Bagby GJ, Lang CH, Spitzer JJ: Effect of acute alcohol administration on TNF- $\alpha$ binding to neutrophils and isolated liver plasma membranes. Alcohol Clin Exp Res 16:533-538, 1992

35. Howard M, Muchamuel T, Andrade S, Menon S: Interleukin 10 protects mice from lethal endotoxemia. J Exp Med 177:1205-1208, 1993

36. Standiford T, Strieter R, Lukacs N, Kunkel S: Neutralization of IL-10 increases lethality in endotoxemia. Cooperative effects of macrophage inflammatory protein-2 and tumor necrosis factor. J Immunol $155: 2222-2229,1995$

37. Wagner F, Fink R, Hart R, Lersch C, Dancygier H, Classen M: Ethanol inhibits interferon-gamma secretion by human peripheral lymphocytes. J Stud Alcohol 53:277-280, 1992

38. Wegmann TG, Hui L, Guilbert L, Mosmann TR: Bidirectional cytokine interactions in the maternal-fetal relationship: Is successful pregnancy a $T_{H} 2$ phenomenon? Immunol Today 14:353-356, 1993

39. Szabo G, Verma B, Catalano D: Selective inhibition of antigenspecific $T$ lymphocyte proliferation by acute ethanol exposure: The role of impaired monocyte antigen presentation capacity and mediator production. J Leukoc Biol 54:534-544, 1993

40. Victorov AV, Hoek JB: Secretion of prostaglandins elicited by lipopolysaccharide and ethanol in cultured rat Kupffer cells. Biochem Biophys Res Comm 215:691-697, 1995

41. Fradin A, Henson PM, Murphy RC: The effect of ethanol on arachidonic acid metabolism in the murine peritoneal macrophage. Prostaglandins 33:579-589, 1987

42. Hwang DH, Chanmugam P, Hymel G, Boudreau M: Effects of chronic ethanol ingestion on arachidonic acid metabolism in rat tissues and in vitro effect of ethanol on cAMP in platelets. Prost Leukoc Med 26:299-305, 1987

43. Strassmann G, Patil-Koota V, Finkelman F, Fong M, Kambayashi $T$ : Evidence for the involvement of interleukin 10 in the differential deactivation of murine peritoneal macrophages by prostaglandin $E_{2}$. J Exp Med 180:2365-2370, 1994

44. Salo RJ, Maddux NL, Bleam DK: Effect of prostaglandins on interferon synthesis in murine macrophage-like cell lines. Immunobiology 171:155-163, 1986

45. Vervliet $G$, Deckmyn $H$, Carton $H$, Billiau A: Influence of prostaglandin $E_{2}$ and indomethacin on interferon- $\gamma$ production by cultural peripheral blood leukocytes of multiple sclerosis patients and healthy donors. J Clin Immunol 5:102-108, 1985

46. Ducatenzeiler A, Menezes J: Human gamma interferon induction by staphylococcal protein A: Effector cells, kinetics and the effect of prostaglandin, indomethacin, ibuprofen and aspirin. Int $\mathrm{J}$ Immunopharmacol 10:81-91, 1988

47. van der Pouw Kraan TCTM, Boeije LCM, Smeenk RST, Wijdenes $\mathrm{J}$, Aarden LA: Prostaglandin- $\mathrm{E}_{2}$ is a potent inhibitor of human interleukin 12 production. J Exp Med 181:775-779, 1995 